\title{
Letter
}

Arq Neuropsiquiatr 2010;68(1):130-131

\section{Conservative treatment of large spontaneous spinal extradural hematoma}

\author{
Moisés Heleno Vieira Braga', Rafael Augusto Castro Santiago Brandão', \\ Gervásio Teles C. de Carvalho², Cristiane Duarte Santos³, \\ Marcelo Sartori de Abreu ${ }^{4}$
}

Spontaneous epidural hematoma (SEH) is a rare condition, which, in most cases, requires surgical treatment due to neurological worsening that occurs within the first 12 hours after the ictus.

We describe the surgical indication for $\mathrm{SEH}$ and show that conservative treatment might be a treatment option in selected cases, presenting good outcomes.

\section{CASE}

A 47-year-old woman had deep venous thrombosis and was using an oral anticoagulant. On July 28, 2007, the patient developed sudden signs and symptoms of intense back pain, followed by rapidly progressing paraparesis associated with urinary retention 12 hours later. The patient thus sought a hospital emergency service.

On July 30, 2007, magnetic resonance (MR) imaging of the cervicothoracic spine showed a large anterior extradural hematoma extending from $\mathrm{C} 7$ to $\mathrm{T} 6$ and causing marked compression of the underlying spinal segment, and an area of edema or ischemia of the spinal segment corresponding to vertebral bodies C7 to T6 (Fig 1).

Conservative treatment was chosen because of the presence of important coagulation disorder and the progressive neurological improvement of the patient after the first 24 hours of ictus. In view of her low prothrombin time, the patient received activated factor VII for correction of the coagulation disorder and to prevent new bleedings.

The patient presented important progressive improvement of the sensorimotor deficit in the lower limbs. Control RM imaging of the cervicothoracic spine performed on August 8, 2007 revealed almost complete absorption of the hema-

\section{Correspondence Moisés Heleno Vieira Braga Hospital da Santa Casa Departamento de Neurocirurgia da Faculdade de Ciências Médicas de Minas Gerais 30130-110 Belo Horizonte MG - Brasil E-mail:moizeusss@yahoo.com.br}

Received 13 February 2009 Received in final form 5 May 2009 Accepted 11 August 2009

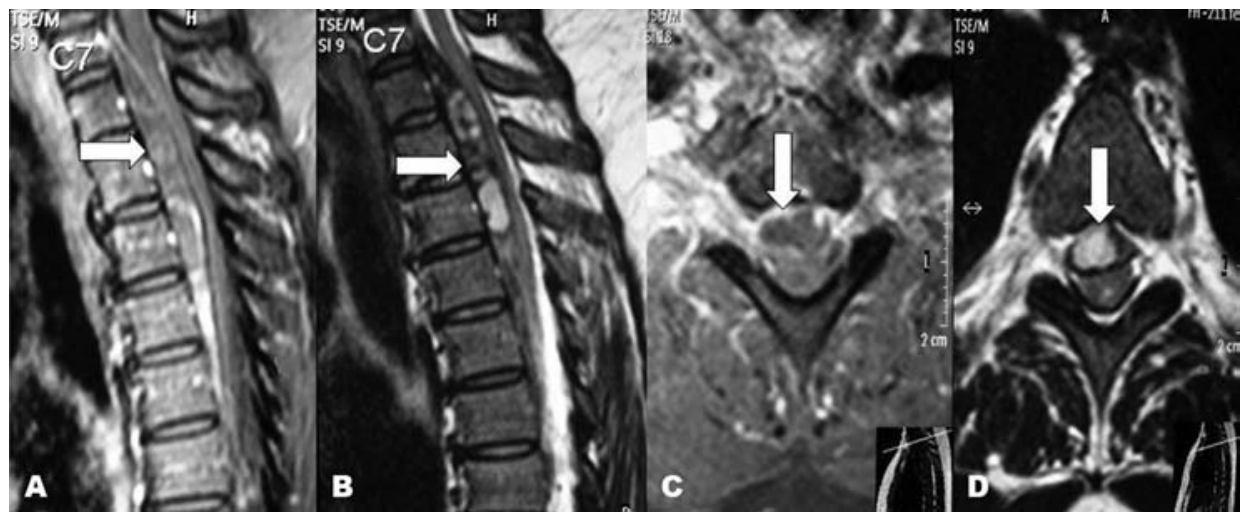

Fig 1. [A] T1-weighted sagittal section showing an isointense expansive lesion extending from C7 to T6. [B] Hypo- and hyperintense expansive lesion on T2-weighted sequences extending from C7 to T6. [C] Axial section at the level of T3 showing an isointense expansive lesion on T1-weighted sequences anterior to the spine [D] Axial section at the level of T3 showing a hyperintense expansive lesion on T2-weighted sequences compatible with bleeding and a hyperintense intramedullary signal compatible with edema.

\section{TRATAMENTO CONSERVADOR DE VOLUMOSO HEMATOMA EXTRADURAL ESPINHAL ESPONTÂNEO}

Santa Casa Hospital, Department of Neurosurgery, Faculty of Medical Science of Minas Gerais, Belo Horizonte MG, Brazil: ${ }^{1}$ Resident of Neurosurgery; ${ }^{2}$ Professor of Neurosurgery; ${ }^{3}$ Neurologist at Biocor Hospital; ${ }^{4}$ Neurosurgeon. 


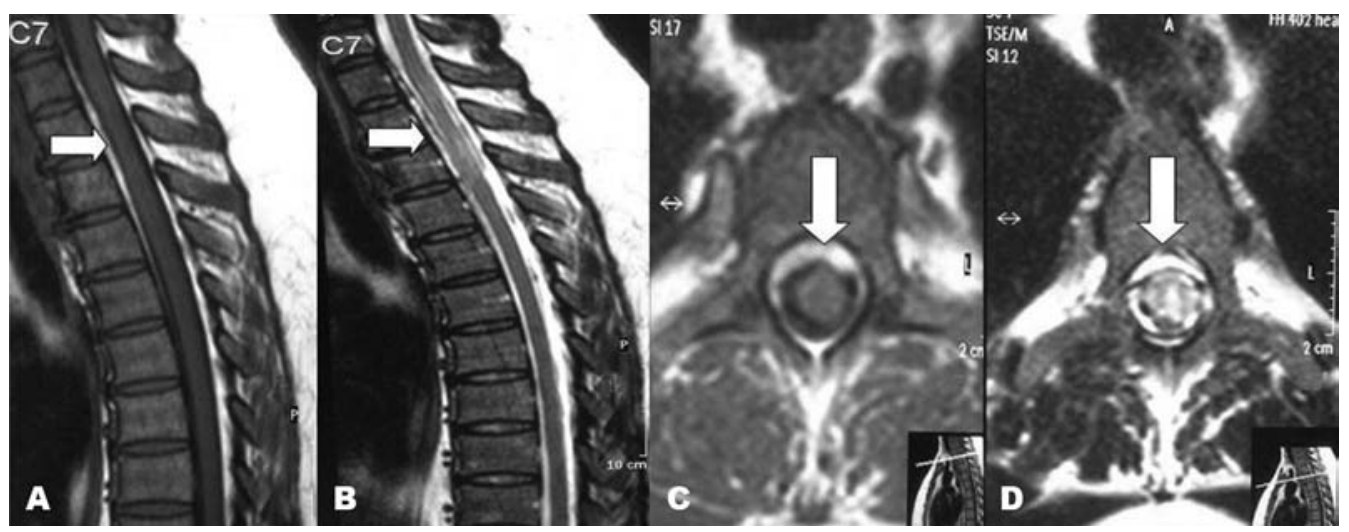

Fig 2. [A] T1-weighted sagittal section showing normal patterns. [B] T2-weighted sagittal section demonstrating significant absorption of the epidural hematoma. [C] T1-weighted axial section at the level of T3 showing normal patterns. [D] T2-weighted axial section at the level of T3 showing a hyperintense intramedullary area compatible with edema.

toma, with only an intramedullary hypersignal remaining (Fig 2). The patient continued physiotherapy and walks without support, shows no motor deficits and only presents a proprioceptive deficit in the lower limbs.

\section{DISCUSSION}

$\mathrm{SEH}$ is a rare hemorrhagic complication ${ }^{1,2}$ and more than 600 cases have been published in the literature so $\mathrm{far}^{3,4}$. Various diseases are those increasing pressure in the extradural veins, such as small traumas, sneezing, vomiting, evacuation and pregnancy can cause this type of hematoma. At present, the cause of hemorrhage is unknown in $40 \%$ of cases.

The incidence of SEH is higher among males and the condition is more common in the lumbar region; howev$\mathrm{er}$, in patients below the age of 40 the cervical region is the most affected ${ }^{5}$. Arterial origin of SEH has been suggested by some investigators in view of the proximity of the epidural arteries to the nerve roots, with reports of cases of nerve root pain as the initial symptom. Acute chest or cervical pain followed by sensory or motor deficits has been suggested to be a strong indicator of the presence of $\mathrm{SEH}^{6}$. Serizawa et al. ${ }^{7}$ described a case of SEH characterized by intense back pain but without neurological deficits.

Most authors recommend surgical treatment as the main therapeutic option for patients with marked neurological deficits, Frankel grade A-B ${ }^{8}$ or sustained deficits ${ }^{2,4,8}$. Conservative treatment is indicated for patients with mild neurological deficits, such as Frankel grade D-E ${ }^{8}$, or patients showing progressive neurological improvement ${ }^{9,10}$. Patients without neurological deficits can also be treated conservatively ${ }^{4}$. It should be emphasized that the size or thickness of the hematoma is not an indicator to be used to determine whether surgical or conservative treatment is the best management ${ }^{4}$.

Controversy exists in the literature regarding the ap- propriate time for surgery, with divergences in the best timing of surgery for drainage of $\mathrm{SEH}^{4,6}$. Clinical criteria are paramount to determine the exact time for surgery in order to obtain the best outcomes ${ }^{8}$.

In the present case, the decision of conservative treatment was made because more than 12 hours had elapsed between the onset of symptoms and diagnosis, and because of the presence of blood dyscrasia and especially because of the important progressive neurological improvement of motor and sensory deficits after MR diagnosis.

In summary, spontaneous epidural hematoma continues to be a condition for urgent neurosurgery whose outcomes are favorable. However, conservative treatment is an option for patients with mild neurological deficits or who present progressive neurological improvement.

\section{REFERENCES}

1. Wagner S, Forsting M, Hacke W. Spontaneous resolution of a large spinal epidural hematoma: case report. Neurosurgery 1996;38:816-818

2. Lawton MT, Porter RW. Surgical management of spinal epidural hematoma: relationship between surgical timing and neurological outcome. J Neurosurg 1995;83:1:1-7.

3. Shimada N, Sugawara T, Itoh Y, et al. Four cases of spontaneous spinal epidural hematoma. No Shinkei Geka 2005;33:163-168.

4. Kreppel D, Antoniadis G, Seeling W. Spinal hematoma: a literature survey with meta-analysis of 613 patients. Neurosurg Rev 2003;26:1-49.

5. Delgadiho VM, Caberlin SR, Mazzali M, Oliveira SM. Hematoma espinhal extradural: rara complicação durante terapia anticoagulante. Arq Bras Cardiol 1994;62:113-114.

6. Tailor J, Dunn IF, Smith E. Conservative treatment of spontaneous spinal epidural hematoma associated with oral anticoagulant therapy in a child. Child's Nerv Syst 2006;22:1643-1645.

7. Serizawa Y, Ohshiro K, Tanaka K. Spontaneous resolution of an acute spontaneous spinal epidural hematoma without neurological deficits. Intern Med 1995;34:992-994

8. Torres A, Acebes JJ, Cabiol J. Spinal epidural hematomas: prognostic factors in a series of 22 cases and a proposal for management. Neurocirugia (Astur) 2004; 15:353-359.

9. Hentschel SJ, Woolfenden AR, Fairholm DJ. Resolution of spontaneous spinal epidural hematoma without surgery: report of two cases. Spine 2001;26: 525-527.

10. Pahapill PA, Lownie SP. Conservative treatment of acute spontaneous spinal epidural hematoma. Can J Neurol Sci 1998;25:159-163. 